CS А. Грённ и О. Клонова (ред.) Русский язык в контрастивном аспекте, Oslo Studies in Language 2(3), 2010. 575-589. (ISSN 1890-9639)

http://www.journals.uio.no/osla

\title{
ПРЕДСТАВЛЕНИЕ КУЛЬТУРЫ В РУССКОМ И НОРВЕЖСКОМ ЯЗЫКАХ
}

\author{
ТАТЬЯНА МЕЛЕНТьЕВА \\ Мурманский гуманитарный институт
}

Голландский социолог Гирт Хофстеде дает следующее определение культуры. Культура это «коллективная ментальная запрограммированность, часть предопределенности нашего восприятия мира, общая с другими представителями нашей нации, региона или группы и отличающая нас от представителей других наций, регионов и групп» (Грушевицкая 2003, 243).

В настоящее время стало актуальным изучение проблем соотношения и взаимосвязи языка, культуры и этноса.

Жизнь общества и лексика языка тесно связаны между собой. Слова любого языка могут многое рассказать о культуре, традициях, менталитете того или иного народа.

Проблемы, связанные с культурно-обусловленными законами языкового общения, входят в сферу интересов и изучения многих наук, например: культурной антропологии, социолингвистики, этнолингвистики, лингвострановедения и лингвокультурологии.

В качестве отрасли науки о языке, исследующей проявления культуры народа, которые отразились и закрепились в языке, всё большее распространение в последнее время получает лингвокультурология.

По мнению В. В. Воробьева, лингвокультурология - это «новая филологическая дисциплина, изучающая определенным образом отобранную и организованную совокупность культурных ценностей, исследующая живые коммуникативные процессы порождения и восприятия речи, опыт языковой личности и национальный менталитет, она дает системное описание «языковой картины мира...» (Тер-Минасова 2000, 18).

Под языковой картиной мира стоит понимать исторически сложившуюся в обыденном сознании данного языкового коллектива и отраженную в языке совокупность представлений о мире, определенный способ концептуализации действительности (Маслова 2004, 64).

Многие исследователи едины во мнении, что язык и культура находятся в тесной взаимосвязи. Язык и культура имеют много общего: во-первых, культура и язык - это формы сознания, которые отображают мировоззрение человека; во-вторых, культура и язык находятся в постоянном диалоге между собой; в-третьих, субъектом культуры и языка всегда является индивид, 
личность или общество. Взаимосвязь языка и культуры может проявляться в коммуникативных процессах, при формировании языковых способностей человека, а также при формировании родового, общественного человека (Маслова 2004, 60).

В культурологической литературе значение языка и культуры часто сводится к следующим образным утверждениям:

- Язык - это зеркало культуры, в котором отражается мир, окружающий человека, особенности его самосознания, менталитета и национального характера, обычаи, традиции, устои, нормы и ценности, картина мира.

- Язык - это кладовая, или копилка культуры, так как в языковой системе (в лексике, грамматике, в идиоматике, в пословицах и т.д.) хранятся все знания, умения, материальные и духовные ценности того или иного народа.

- Язык - это передатчик или носитель культуры, с помощью которого все накопленные знания о мире, нормах и ценностях передаются из поколения в поколение.

- Язык - это инструмент, орудие культуры. Через культуру народа, использующего тот или иной язык как средство общения, происходит формирование личности человека, носителя языка (Грушевицкая 2003, 157).

Существует взаимодействие между словарным запасом и приоритетами общества на определенном историческом этапе. По мнению Г. В. Елизаровой можно выделить несколько типов соотношения слов в разных языках (Елизарова 2001, 42).

В первую очередь, встречается ограниченный набор слов, так называемых культурных универсалий, значения которых могут быть соотнесены полностью или в большей степени со значениями соответствующих слов в другом языке.

К культурным универсалиям относятся следующие слова: земля (jord), poдина (hjemland), мир (verden), религия (religion), труд (arbeid), семья (familie), материнство (moderskap), рождение (fødsel), жизнь (liv), смерть (død), любовь (kjærlighet) и т.д.

Сравним толкования некоторых из этих слов в русском и норвежском языках. Проанализируем определения слов, представленные в русских и норвежских толковых словарях. ${ }^{1}$

\footnotetext{
${ }^{1}$ Определения русских слов взяты из толковых словарей Д. Н. Ушакова, В. И. Даля, БСЭ. Определения норвежских слов взяты из Norsk ordbok, A. Landfald, К. M. Paulssen и электронных словарей, представленных на сайте http://www.dokpro.uio.no/perl/ordboksoek/ordbok.cgi.
} 
Русский язык ЗЕМЛЯ

1. Третья от Солнца планета Солнечной системы, вращающаяся вокруг Солнца и вокруг своей оси. Земля планета людей.

2. Суша в противоположность водному или воздушному пространству.

3. Почва, верхний слой коры нашей планеты, поверхность.

4. Рыхлое темно-бурое вещество, входящее в состав коры нашей планеты.

5. Страна, государство, а также вообще какая-нибудь большая территория Земли.

6. Территория с угодьями, находящаяся в чьем-либо владении, пользовании.

\section{Норвежский язык} JORD

1. klode som menneskene bor på, planeten Tellus

\section{2. jordoverflaten}

3. jordoverflate, jordbunn som gjenstand for dyrking

4. løse avleiringer som vekster kan leve i

5. territorium, landområde eller statsområde

6. landbruksareal

Мы видим, что значения слова «земля» в русском и норвежском языках совпадают.

Приведём ещё один пример:

MATb

1. Женщина по отношению к её детям.

2. Самка по отношению к её детёнышам.

3. перен. То, что является источником, давшим жизнь кому/чемунибудь, откуда черпают силу, энергию, жизненность.

4. Обращение к пожилой женщине (просторечное).

5. Обращение, присоединяемое к имени или званию монахини (иерковное).
MOR

1. kvinne i forholdet til barn hun har født

2. kvinnelig familieoverhode

3. kvinne som forestår og styrer en husholdning

4. opphav

5. i tiltale til kvinner

6. særl som førsteledd i sms: livmor, i ord som morkake, mormunn

И в русском и в норвежском языках слово «мать» используется в отношении женщины, давшей жизнь, или при обращении к представительницам 
женского пола (однако в русском языке это обращение используется в отношении женщины более старшего возраста). Для передачи 2-го значения русского слова «мать» в норвежском языке используют слово hunn (hunndyr, hunnfugl). Значение слова «мать» как «источника жизни, силы или энергии» (например, мать природа, Родина-мать) в норвежском языке не представлено.

На основе словарных статей мы видим, что основные значения выбранных слов совпадают.

Вторую группу слов, характеризующих связь языка и культуры, составляют ключевые или центральные слова, значимые для представителей той или иной культуры. Отличительным признаком таких слов является их частотность употребления. Например, в русском языке - это слова душа, воля, удаль, тоска и др. Норвежские эквиваленты для названных слов sjel, vilje, djervhet, tungsinn не могут раскрыть все те значения, которые вкладывает в эти концепты русский человек.

С точки зрения русского языка и культуры «душа» - это

1. нематериальное начало жизни, противополагаемое телу; бесплотное существо, остающееся после смерти человека (религиозное представление);

2. совокупность психических явлений, переживаний, основа психической жизни человека;

3. внутренний, психический мир человека;

4. свойство характера, основные черты личности, а также человек с теми или иными свойствами;

5. чувство, отзывчивость, пыл;

6. вдохновитель, главный организатор, центральная личность (чаще разговорное);

7. сущность, самое главное;

8. человек (разговорное);

9. крепостной крестьянин (историческое);

10. дружеское фамильярное обращение к кому-нибудь, чаще с прибавлением слова «моя» (разговорное). 
Слово душа может быть переведено на норвежский язык следующим образом:

1. SJEL

i) в значении душевная часть человека с точки зрения религии или отношения к Богу, например: be for sin sjels frelse;

ii) в значении внутренний мир, например: med liv og sjel-душой и телом;

iii) в значении характер, темперамент, например: en god sjel - добрая душа; å legge hele sin sjel $i-$ вкладьвать всю душу во что-то;

iv) в значении вдохновитель, например: han er sjelen i prosjektet - он душа проекта;

v) в значении человек, индивид, например: det var ikke en levende sjel der;

2. INNE в значении внутренний мир, например: innerst inne - в глубине души;

3. HJERTE

i) в значении особенности природы человека, например: av hele sitt hjerte - от всей души;

ii) о настроении, например: han er lett om hjertet - y него легко на душе;

4. SINNE, если речь идет о мыслях человека, например: hva har han i sinne? что у него на душе?

5. PERSON, если речь идет о количестве лиц, например: det er 5 personer i familien - в семье пять душ.

Ни одно из этих слов норвежского языка не может передать всех оттенков значения русского слова «душа».

Рассмотрим в качестве примера норвежское слово LIKESTILLING. Оно намного шире по значению по сравнению с русским словом равноправие. В России под этим словом понимается, прежде всего, равенство граждан перед государством, законом, судом, т.е. равенство прав, свобод и обязанностей граждан (Большая Советская Энциклопедия). В норвежской лингвокультуре такое значение может быть передано словом rettferdighet - npaво, справедливость. Помимо значений «равенство прав, свобод и обязанностей граждан» понятие likestilling может означать также «равные возможности для мужчин и женщин, например, в отношении заработной платы за один и тот же вид деятельности, в отношении карьерного роста и занимаемой должности». Равноправие действует применимо к разным категориям граждан независимо от их половой, возрастной, расовой, религиозной принадлежности и функциональных особенностей. 
Другим примером ключевого слова норвежского языка является концепт VELFERD - благосостояние. Для русского человека благосостояние ассоциируется с достатком, имуществом, богатством, мерой, степенью обеспеченности людей жизненными благами, средствами существования, то есть на первый план выступает материальный аспект (Большой экономический словарь). В русском языке слово благосостояние чаще употребляется в экономических кругах, в то время как в норвежском языке, это в большей степени социальное и политическое понятие. Под благополучием в норвежской лингвокультуре понимается стремление человека к всестороннему развитию при активном содействии государства, что находит отражение и в языке. Сейчас часто звучит слово VELFERDSSTAT (государство благополучия), по аналогии с английским WELFARE STATE, чTо означает «государство, принимающее на себя основную долю социальных расходов» (Большой экономический словарь). В частности, это понятие встречается в программах многих норвежских политических партий.

Кроме того, в норвежском обществе благополучие тесно связано с равенством (возможно использование слова LIKEVERD) и предоставлением одинаковых возможностей для всех категорий граждан. Плюс ко всему понятие VELFERD имеет еще один оттенок значения TRYGGHET, чTо значит «гарантия, безопасность, уверенность в завтрашнем дне». Из примеров видно, что в норвежском языке слово VELFERD включает материальный, духовный и социальный аспекты значения и употребляется в более широком смысле, по сравнению с русским языком.

Такие слова как ENKELTHET, ÆRLIGHET, PAKKELøSNING, SAKLIGHET и OPPRIKTIGнЕт являются, по мнению Эриксена (Eriksen 1993), значимыми для носителей норвежского языка и культуры. Значения этих слов являются культурно-специфическими и не имеют однозначных соответствий в русском языке.

Например, слово saklighet переводится на русский язык как «практичность и деловитость», но в русском языке не находит отражения значение этого слова, как «придерживающийся основной темы разговора, не отступающий от темы».

Третью группу слов, определяющих взаимосвязь лексики языка и культуры, составляет безэквивалентная лексика (Елизарова 2001, 39). о безэквивалентной лексике принято говорить в тех случаях, когда соответствие той или иной лексической единице одного языка в словарном составе другого языка полностью отсутствует. Под безэквивалентной лексикой понимают «слова, служащие для выражения понятий, отсутствующие в иной культуре и в ином языке, слова, относящиеся к частным культурным элементам, т.е. к культурным элементам, характерным только для культуры $A$ и отсутствующим в культуре $B$, а также слова, не имеющие перевода на другой язык, одним словом, не имеющие эквивалентов за пределами языка, к которому они принадлежат» 
(Виноградов 2001, 37). При этом отмечается, что характерной чертой безэквивалентных слов является их непереводимость на другие языки с помощью постоянного соответствия, их несоотнесенность с некоторым словом другого языка. Понять такую лексику можно, если человек, говорящий на иностранном языке, владеет фоновыми знаниями, под которыми мы понимаем «совокупность представлений о том, что составляет реальный фон, на котором развертывается картина жизни другой страны, другого народа» (Виноградов $2001,38)$. Фоновые слова представляют собой значительный интерес при исследовании сложного взаимодействия языка и культуры. Е. И. Шумагер отмечает, что фоновые слова - это лексические единицы, на первый взгляд, самые обычные, свободно переводящиеся на иностранные языки, которые содержат, однако, ценную информацию о специфически национальной внеязыковой деятельности. В частности, одной из групп фоновых знаний являются реалии.

Реалии - это «названия присущих только определенным нациям и народам предметов материальной культуры, фактов истории, государственных институтов, имена национальных и фольклорных героев, мифологических существ и т.п.» (Виноградов 2001, 39). Наиболее полное определение реалии дают болгарские ученые С. Влахов и С. Флорин: «Реалии - это слова (и словосочетания), называющие объекты, характерные для жизни (быта, культуры, социального и исторического развития) одного народа и чуждые другому, будучи носителями национального и/или исторического колорита, они, как правило, не имеют точных соответствий (эквивалентов) в других языках, и, следовательно, не поддаются переводу на общем основании, требуя особого подхода» (Влахов 1986, 14).

Реалии характерны для любого языка, им присущ ярко выраженный национальный колорит, поэтому можно говорить о национальных реалиях, то есть предметах, явлениях, традициях, обычаях, составляющих специфику данной социальной общности или этнической группы.

В настоящее время существует несколько вариантов классификаций реалий и культурно-маркированных единиц. В статье за основу взята классификация В. С. Виноградова, который считает, что содержание фоновой информации охватывает, прежде всего, специфические факты истории и государственного устройства национальной общности, особенности географической среды, характерные предметы материальной культуры прошлого и настоящего, этнографические и фольклорные понятия и т.п. Приведем примеры лексических единиц, передающих фоновую информацию в рамках нескольких тематических групп в русском и норвежском языках. 
ТЕМАТИЧЕСКИЕ

грУпПЫ Слов

1. Лексика, называющая бытовые реалии

a) Жилище, имущеСтво;

б) Одежда, уборы;

в) Пища, напитки;

г) Виды труда и занятия, названия лиц, занимающихся этими видами занятий;

д) Денежные знаки, единицы меры;

е) Музыкальные инструменты, народные танцы и песни, исполнители;

ж) Народные праздники, игры. русский язык

а) Изба, двор, дача, Хрущевка, Сталинка, огород и т.д.

б) Сарафан, тулуп, шапка-ушанка, валенки и т.д.

в) Блины, щи, борщ, пельмени, квас, морс, сушка, расстегай, кулебяка, манка и т.д.

г) Золотарь, передовик, стахановец, колхоз, рекетир, валютчик и т.д.

д) Рубль, червонец, лимон, пуд, аршин, и т.д.

е) Балалайка, баян, гусли, хоровод, казачок, яблочко и т.д.

ж) Жмурки, Иван Купала, масленица, святки, калядки, кулич и т.д.
НОРВЕЖСКИЙ яЗЫК

a) hytte, enebolig, gård, bygård, hybel osv.

б) bunad, russelue, mariusgenser, olabukser osv.

в) fiskebolle, lutefisk, fårikål, rømmegrøt, pinnekjøtt, brunost osv. г) gårdbruker, bonde, osv.

д) krone, øre osv.

e) hardingfele, lur, langeleik, bukkehorn, munnharpe osv.

ж) 17. mai, barnetog, julebukk osv.

2. Лексика, называюСнегурочка, Дед Моjulenisse, troll, huldra, щая этнографические и мифологичероз, Емеля, Иван-дурак, Odin, Tor, Freia, osv. поп и т.д. ские реалии

3. Лексика, называю-

Тайга, степь, тундра, сопка и т.д. lyng, torsk, fjord, holme, jugendstil, osv. природы 
4. Лексика, называющая реалии государственно-административного устройства и общественной жизни (актуальные и исторические)

a) Административные единицы и государственные институты;

б) Общественные организации, партии;

в) Промышленные предприятия, торговые заведения;

5. Лексика, называющая ономастические реалии

а) Антропонимы;

б) Топонимы;

в) Имена литературных героев;

г) Названия компаний, театров, магазинов, аэропортов и т.п.

6. Лексика, отражающая ассоциативные реалии а) Поместье, околоток, округ, Дума, царь, большевик, новый русский и т.д.

б) ЛДПР, НКВД, Единая Россия и т.д.

в) Детский мир, Гум, Цум и т.д. a) fylke, kommune, Storting, konge osv.

б) AP, SV osv.

B) Statoil, Troll, Hydro, SAS, Freia osv.
Путин, Иван Грозный, Петр I, Москва, Бородино, Детский мир, Большой театр, Внуково, Домодедово и т.д.
Harald Hårfagre, Olav den hellige, Oslo, Eidsvoll, Akershus, Gardermoen, Fram, osv.
Наташа Ростова, обломовщина, Тарас Бульба, Леня Голубков и т.д.
Tiger (символ Осло), Kristin Lavransdatter, Lillelord, Peer Gynt, osv.

Из примеров видно, что в реалиях наиболее наглядно проявляется близость между языком и культурой; эти лексические единицы быстро реагируют на все изменения в развитии общества.

Наконец, в отдельную группу можно выделить лексику с культурным компонентом значения - это слова, отражающие культурно-специфические понятия того или иного языка. На поверхности, в своих лексических значениях они совпадают, но отличаются значениями культурными. 
Например: русское слово дом и два норвежских HUS, нJEм. В русской лингвокультуре под домом понимается (Толковый словарь Уиакова):

1) жилое здание, строение (деревянныцй дом);

2) жилое помещение, квартира (вам и́з дому звонили.);

3) учреждение для обслуживания культурно-бытовых нужд трудящихся или отдельного круга лиц, помещающееся обычно в отдельном здании (дом моряка, дом отдыха, дом культурь, дом кино, дом ребенка, пушкинский дом);

4) заведение, предприятие (торговыци дом, шоколадный дом, дом терпимости, питейныц̆ дом, игорныцй дом);

5) все жильцы какого-либо дома (весь дом выбежал на крик.);

6) семья, люди, живущие вместе, одним хозяйством (в гости всем домом поили.);

7) хозяйство отдельной семьи (она на весь дом ведет.);

8) династия, род (истор.) (дом романовых);

9) в детских играх, основанных на преследовании (пятнашки, прятки и др.) - место, где по правилам игры нельзя преследовать (я в домике.).

В норвежском языке слово нus имеет следующие значения:

1) здание с крышей и стенами [bygning med tak og vegger] (et toetasjes hus двухэтажныци дом, guds hus - церковь);

2) место жительства, домашний очаг, хозяйство [bosted, hjem, husholdning] (grunnlegge et hus - обосноваться, kona i huset - хозяйка дома/хранительница очага);

3) люди, живущие в одном доме, семья, близкие [personer som bor i et hus, hus-stand, familie] (vekke hele huset - будить всю семью, еn venn av husetдруг семьи, kongehus - королевский дом, være i hus med en - жить под одной крыцией);

4) большое промышленное/служебное предприятие, фирма [større forretningstiltak] (handelshus - торговьцй дом);

5) часть английского парламента [del av parlament] (overhus - верхняя палата, underhus - нижняя палата); 
6) футляр, контейнер, емкость для хранения [beholder, hylster] (blekkhus - чернильница, brillehus - футляр для очков, kreтmеrhus - пакетик, кулёк);

7) в покере (få fullt hus i poker: få tre like og et par-иметь на руках пару и три карты одной масти);

8) разг. скандал, свара, шум (holde et forferdelig hus - шуметь, скандалить, безобразничать в доме);

9) театральный зал, кинозал, концертный зал (fullt hus - nолный cбор, det er utsolgt hus - все билеты проданы).

Рассмотрим, какие значения имеет норвежское слово нјЕм:

1) жилище, местопребывания (о семье, домочадцах) [bolig, fast oppholdssted (for familie, husstand)] (få sitt eget hjeт - получить собственное жилье; denne trange hybelen har vært mitt hjem i to år - эта тесная комнатка стала моим домом/ местом жительства на два года);

2) убежище, богадельня, приют для тех, у кого нет дома [bygning, anstalt som er bolig for folk som ikke har et hjem] (barnehjem - детский дом, hvilehjem дом отдыха, pleiehjem - дом призрения, sykehjem - дом инвалидов);

3) семья, близкие [husstand, familie] (få hus og hjem - обзавестись семьей);

4) родной край, родная сторона, родина [hjemland] (å lengte hjem - скучать no дому/родине).

Из примеров видно, что большая часть значений слов дом, нUS и нJEм совпадает в двух языках, но есть также и отличия в коннотациях.

В русском языке дом - это любое здание, где живет и работает человек. В норвежском слово нUS означает место жительства, но не работы, тогда говорят bygning. Жилой дом - это bolighus. При назывании учреждений используются оба варианта слова нUS и нјЕм, например: kulturhus (дом культурь), aldershјет (дом престарельх).

Стоит также обратить внимание на тот факт, что в норвежском языке можно выявить большое количество составных слов с корнем hjem- и hus-. Например:

hjemby - родной город

hjemfaren - (женатый) имеющий свой дом

hjemfart - возвращение на родину

hjemfast - оседлый, имеющий постоянное место жительства

hjemland - родной край/сторона 
hjemmeindustri - кустарная промышленность

hjemmefronten - Силы сопротивления (в период Второй Мировой войны)

hjemmevant - чувствующий себя как дома

husapotek - домашняя аптечка

husarbeid - работа по дому

husfar - глава семьи

husholdning - ведение домашнего хозяйства

husflid - кустарная промышленность

Особого внимания при анализе взаимодействия лексики и культуры заслуживает проблема сочетаемости. Каждое слово каждого языка имеет свой, присущий только этому языку запас сочетаемости, тогда получается, что сочетаемость слов тоже может быть национальна (Тер-Минасова 2000, 52). Приведём примеры:

русский язык

В русском языке мы говорим:

- одержать победу (å vinne seier) и потерпеть поражение (å lide et nederlag);

- нанести визит (å avlegge et besøk), но нельзя сказать сделать (оказать) визит, хотя мы можем сказать оказать честь (å gjøre/vise ære på), оказать помощь (å yte støtte);

- язык заплетается (tungen vil ikke lystre), чего нельзя сказать о губах;

- склонить голову (bøye seg for), преклонить колено (knele for), но не *npeклонить голову;

- круглый год (сутки) (hele året/dagen), но не *круглый час или месяи;

- глубокая ночь (осень) (sen natt/høst), но не день (весна);

- бархатный сезон (ettersommeren ved svartehavet), но не периодили месяи.

Примечательно, что последнее словосочетание является типично русским и характеризует отдых только на Черном море.

НОРвЕЖСКИй яЗЫк

Примеры, иллюстрирующие особенности сочетаемости в норвежском языке:

- å begå selvmord (совершить самоубийство), или ta sitt eget liv (лишить себя жизни). Тогда как конструкция "ta selvmord будет неправильной; 
- å stille spørsmål (задать (поставить) вопрос), sette spørsmålstegn ved (поставить знак вопроса), но нельзя сказать *å stille spørsmålstegn ved;

- å spille stor rolle, å ha stor betydning (иметь большое значение). Ошибочно говорить *spille stor betydning и *å ha stor rolle;

- å utarte (вырождаться), но å arte seg (развиваться, вырастать). Нельзя сказать *å utarte seg.

Если человек не знаком с особенностями лексической сочетаемости слов, то он непроизвольно делает ошибки, когда употребляет слова не в том контексте или переводит эти слова на иностранный язык.

Например, слово книга и его эквивалент в норвежском вок. Слово $b o k$ в норвежском языке встречается во многих составных словах и словосочетаниях, но только в некоторых случаях на русский язык оно может быть переведено, как книга или книжка:

abc-bok - азбука

adressebok - записная книжка

arbeidsbok - рабочая тетрадь

Bøkenes Bok - Библия

å føre bok over utgifter og inntekter - записывать расходы и доходы

Перевод отдельного слова может не совпадать с переводами этого слова в словосочетаниях:

записка - seddel, lapp, lite brev

деловая записка - forretningsbrev

служебная записка - memorandum

объяснительная записка - forklaring

докладная записка - rapport

любовная записка - kjærlighetsbrev

путевые записки - reiseopptegnelser

Еще один пример - слово закрытый. Чаще всего используется слово LUKKET:

en lukket bil - закрытая машина

en lukket veranda - закрытая веранда

en lukket forestilling - закрытый спектакль

en lukket stavelse - закрытый слог

В следующих словосочетаниях это же значение передается несколько иначе, с использованием других лексических единиц: 
закрытое платье - en høyhalset (tett) kjole закрытое голосование - en hemmelig avstemning закрытый поворот - en uoversiktig kurve закрытый гласный - en trang vokal

Из примеров видно, что при выборе слова на иностранном языке нужно учитывать его сочетаемость, так как она зачастую национальна, то есть присуща только данному конкретному слову в данном конкретном языке.

Фразеологический фонд языка тоже может дать материал для анализа. Сравним:

НОРВЕЖСКИЙ

å ha det som plommen i egget

å sove som en stein

å snakke som en foss

å være frisk som en fisk

verken fugl eller fisk

langfingrete русский

как сыр в масле

спать как убитый

трещать без умолку

свеж как огурчик

ни рыба, ни мясо

нечист на руку

На основе анализа лексического материала русского и норвежского языков можно сделать вывод о том, что большинство слов не нейтральны в своих значениях. Некоторые слова связаны с определенными культурными ценностями, другие ассоциируются с культурно-значимыми смыслами.

В заключение стоит отметить, что связь языка и культуры носит релятивный характер. Культура формирует языковую картину мира ее носителя и репрезентируется в структуре соответствующего языка. Культура представляет собой совокупность материальных и духовных ценностей, накопленных и накапливаемых определенной общностью людей, и те ценности одной национальной общности, которые у другой отсутствуют вовсе или существенно отличаются от них, составляют национальный социокультурный фонд, так или иначе находящий свое отражение в языке. Именно на эту часть культуры и эту часть языка следует обращать внимание в переводоведении в целях более полного и глубокого понимания оригинала и воспроизведения сведений об этих ценностях в переводе с помощью языка другой национальной культуры.

При обучении же иностранному языку необходимо использовать принцип культурно-связанного соизучения иностранного (русского/норвежского) и родного (норвежского/русского) языков. Этот принцип предполагает объяснение и демонстрацию неразрывной связи каждого конкретного языка и соответствующей культуры. Реализуя этот принцип, нужно всю работу с лингвистическим материалом, от предъявления лексических единиц и грамматических форм до моделирования речевых актов, сопровождать сопоставлени- 
ем с культурными ценностями. Для формирования представлений о культурных ценностях, отражаемых в структуре и функционировании иностранного языка, требуется его культурно-связанное описание, то есть культурологическая лингвистика.

\section{СПИСОК ЛИТЕРАТУРЫ}

Eriksen, T. H. 1993. Typisk norsk. Essays om kulturen i Norge. C. Huitfeldt forlag. http://folk.uio.no/geirthe/Typisk.html.

Виноградов, В. С. 2001. Введение в переводоведение (общие и лексические вопроcbl). М.: Издательство института общего среднего образования РАО.

Влахов, С. И. 1986. Непереводимое в переводе. Библиотека лингвиста. М.: Издательство «УРСС».

Грушевицкая, Т. Г. 2003. Основы межкультурной коммуникации: учебник для вузов. М: ЮНИТИ-ДАНА.

Елизарова, Г. В. 2001. Культура и обучение иностранным языкам. СПб.: Союз.

Маслова, В. А. 2004. Лингвокультурология. М.: «Академия».

Тер-Минасова, С. Г. 2000. Язык и межкультурная коммуникация: учебное пособие. М.: Слово.

АДРЕС АВТОРА

Татьяна Мелентьева

Мурманский гуманитарный институт

Факультет иностранных языков и журналистики

Мурманск

Россия

tat-sukhareva@yandex.ru 